\title{
Investigation into the Presence or Absence of Solid Particles Generated from Thermal Processes in the Aerosol from an Electrically Heated Tobacco Product with and without Filter Elements
}

\author{
Teemu Kärkelä ${ }^{*}$, Jean-Christophe Ebinger², Unto Tapper ${ }^{1}$, Olivier Robyr ${ }^{2}$, \\ Tauno Jalanti \\ ${ }^{1}$ VTT Technical Research Centre of Finland Ltd., Nuclear Energy, Kivimiehentie 3, 02044 VTT, \\ Espoo, Finland \\ ${ }^{2}$ Microscan Service SA, Rue de la Blancherie 17, CP, 1022 Chavannes-près-Renens, Switzerland
}

\begin{abstract}
Heated Tobacco Products (HTPs) were developed as healthier alternatives to cigarettes, which release thousands of chemicals owing to the combustion of tobacco. One HTP is the Electrically Heated Tobacco System (EHTS) from Philip Morris International, which heats instead of burns the tobacco material and produces significantly fewer emissions than traditional cigarettes, as extensively substantiated by independent research groups. Published studies have also confirmed the absence of solid particles in these emissions, which may be due to the filter elements between the tobacco portion and the mouthpiece in the EHTP; however, to the best of our knowledge, the role of these filters has never been investigated. Thus, to determine whether solid particles formed in any part of the product during use, we collected the aerosol from an EHTP with and without filter elements under heated and unheated testing conditions. Both of the analytical methods we applied showed that no solid particles originating from thermal processes were present in the aerosol.
\end{abstract}

Keywords: Heated Tobacco Product, Aerosol, Heating, Combustion, Solid particles

Received: December 23, 2020 Revised: May 14, 2021

Accepted: May 31, 2021

${ }^{*}$ Corresponding Author: teemu.karkela@vtt.fi

\section{Publisher:}

Taiwan Association for Aerosol Research

ISSN: $1680-8584$ print ISSN: 2071-1409 online

(c) Copyright: The Author(s). This is an open access article distributed under the terms of the Creative Commons Attribution License (CC BY 4.0), which permits unrestricted use, distribution, and reproduction in any medium, provided the original author and source are cited.

\section{INTRODUCTION}

Burning cigarettes produce smoke, which is an aerosol, generated from the products of combustion. Smoke contains and deliver, upon inhalation, more than 6000 chemicals (Rodgman and Perfetti, 2013). The causal relationship between smoking and several diseases is well established (Doll et al., 2004) and public health authorities have proposed that approximately 100 Harmful and Potentially Harmful Constituents (HPHCs) found in smoke may cause smokingrelated diseases such as lung cancer, heart disease, and emphysema (Health Canada, 2000; WHO, 2008; U.S. Food and Drug Administration, 2012). Also, because cigarette smoke is the product of incomplete combustion (Butler and Mulholland, 2004) of tobacco, primary carbon nanoparticles are emitted (Steiner et al., 2016) in addition to the thousands of chemical compounds constituting the smoke. Upon inhalation and deposition in lungs, the inhaled water-insoluble carbon nanoparticles of the smoke are difficult for the body to evacuate, which may trigger the development of diseases and enhance mortality in human (Donaldson et al., 1998; Pope et al., 2002; Bauer et al., 2010; Fariss et al., 2013; You et al., 2015; Klein et al., 2017).

Heated Tobacco Products (HTPs) were recently developed and introduced on the market as better alternatives to cigarettes for adult smokers that would otherwise continue to smoke cigarettes. One such HTP is the Electrically Heated Tobacco System (EHTS) from Philip Morris International also referred to as the "Tobacco Heating System (THS) 2.2" (Cozzani et al., 2020), 
which is commercialized in over 50 markets worldwide under the name of IQOS. The working principle of the EHTS is that a tobacco portion of the consumable (referred to as the "Electrically Heated Tobacco Product [EHTP]" or "Tobacco Stick") is heated instead of being burnt with temperatures not exceeding $320^{\circ} \mathrm{C}$. This results in a very important reduction of HPHCs, by more than $90 \%$, compared to the smoke from a 3R4F reference cigarette (University of Kentucky, Lexington, KY, USA) (Schaller et al., 2016). This is a strong indication that the EHTS aerosol has different physico-chemical properties than cigarette smoke. On top of the substantial reductions observed in the levels of HPHCs in the EHTS aerosol compared with cigarette smoke, a study involving the use of a thermo-denuder and impactors coupled to Scanning Electron Microscopy (SEM) analysis demonstrated that cigarette smoke contains carbon-based nanoparticles in contrast to the EHTS aerosol for which no combustion-related solid particles were observed (Pratte et al., 2017). This supports the evidence that no combustion occurs in the EHTS during use, which was demonstrated in Cozzani et al. (2020) and that the emitted aerosol is the result of heating the tobacco only.

One possible hypothesis to explain the absence of combustion-related solid particles in the EHTS aerosol could be that the different filter elements of the EHTP remove these particles, if they are at all generated. To assess this hypothesis and to evaluate the potential various EHTP filters impact on solid particles filtration, modified EHTPs without the filter elements were produced for the purpose of this study. The aerosol generated from the modified EHTP when used in the EHTS holder was analyzed using two different approaches. In the first approach, a test bench was developed to generate cigarette smoke or EHTS aerosol at room temperature and to collect the emitted particulate matter on a transmission electron microscope (TEM) grid for subsequent analyses using SEM (Kärkelä et al., 2021). Selected grid samples were further heated to $200^{\circ} \mathrm{C}$ in order to remove volatiles/semi-volatiles compounds and the particulate matter residue was re-analyzed using SEM afterwards. To complement these experiments, in the second methodology, the modified EHTPs were used in the EHTS holder and the resulting aerosol was conveyed through a thermo-denuder operated at $300^{\circ} \mathrm{C}$ to remove volatiles and semi-volatiles, according to the method developed by Pratte et al. (2017). Any remaining residues were collected on impactor traps and analyzed using a SEM. As a reference of how detected solid particles in the smoke from combusted cigarette is observed in the different analysis, the smoke from a 3R4F standard reference cigarette were also analyzed alongside the EHTP products as comparator.

\section{ELECTRICALLY HEATED TOBACCO PRODUCT}

The aerosol generated by the EHTP (Smith et al., 2016) was studied. The results were compared with the smoke from 3R4F research cigarette (3R4F, 2020). The EHTP is composed of four main parts (Fig. 1(a)). Tobacco plug contains the processed tobacco leaves to be heated by the EHTS heating blade. The released aerosol transports through a hollow tube to polymer (Polylactic Acid [PLA])-film filter and finally to a cellulose acetate mouthpiece filter before being inhaled by the consumer. These filtration sections cool down the compounds vaporized from the heated tobacco and helps aerosol formation. In addition, the filter elements may also remove possible tobacco leaves fragments from the aerosol. In this work, both a modified EHTP without filter elements and the original EHTP with filter elements were studied, shown in Figs. 1(b) and 1(c).

The EHTS operates at a maximum heating blade temperature of $\sim 350^{\circ} \mathrm{C}$, thus resulting in a maximum EHTP/tobacco stick temperature of $\sim 320^{\circ} \mathrm{C}$ (Cozzani et al., 2020). At this temperature, nicotine and flavors are released while the tobacco temperature is kept sufficiently low to avoid combustion (Smith et al., 2016; Cozzani et al., 2020). Considering the consumer satisfaction, the aerosol temperature decreases within the filtration section to a temperature suitable for inhalation.

The 3R4F standard reference cigarette was chosen as a reference for combusted cigarettes. During cigarette combustion, temperatures are reaching up to $900^{\circ} \mathrm{C}$ (Baker, 1975), releasing smoke that contains nicotine and thousands of other chemicals (Rodgman and Perfetti, 2013). 

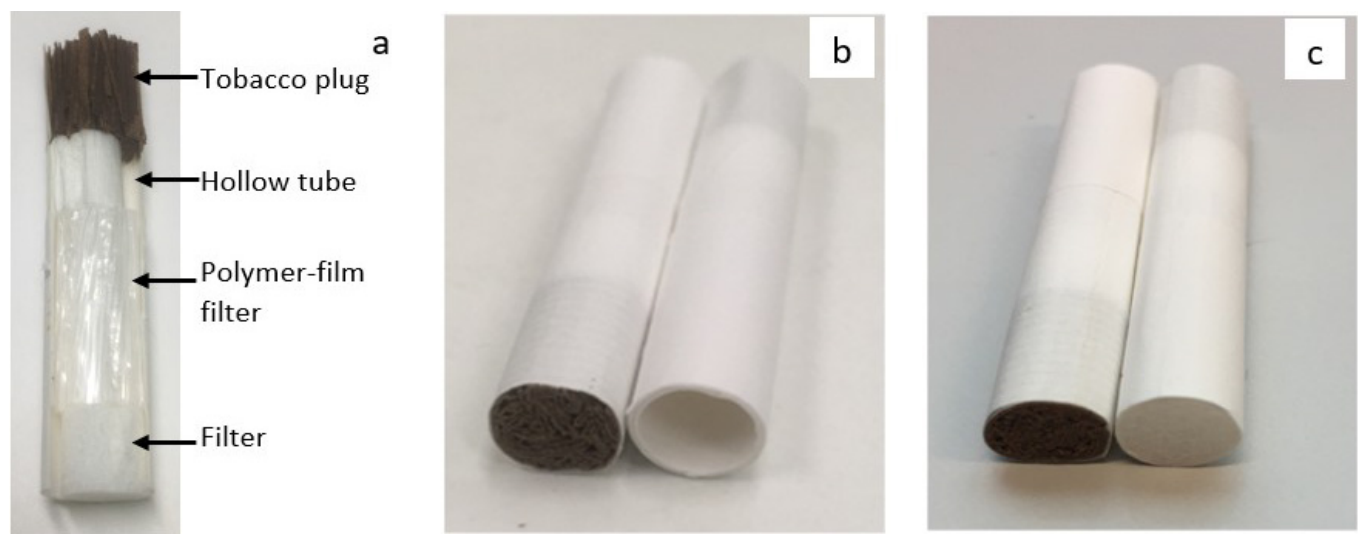

Fig. 1. (a) Four main parts of the EHTP. (b) Modified EHTP without filter elements: The left EHTP shows the tobacco plug and the right one the location where the filter is generally inserted. (c) Original EHTP with filter elements: The left EHTP shows the tobacco plug and the right one the mouthpiece filter.

\section{EXPERIMENTAL METHODS}

\subsection{Method A: Aerosol Dilution}

A schematic diagram of the aerosol dilution method is shown in Fig. 2. The method is described in detail elsewhere (Kärkelä et al., 2021). The test set-up was placed inside a fume hood. A programmable dual-syringe pump (PDSP; Burkhart Messtechnik GmbH, Wedel, Germany) was operated using the Health Canada Intense $(\mathrm{HCl})$ regimen $(55 \mathrm{~mL}$ per $2 \mathrm{~s}$ puff, inter-puff $30 \mathrm{~s}, 10$ puffs for 3R4F reference cigarettes and 12 puffs for the EHTS) to generate cigarette smoke and aerosols from either the modified EHTP without filter elements or the EHTP with filter elements. The test item (cigarette or EHTP as part of the EHTS) was positioned at the inlet of the PDSP, inside a plastic box, flushed with an air flow of $1.5 \mathrm{~L} \mathrm{~min}^{-1}$ to ensure a temperature-controlled $\left(20^{\circ} \mathrm{C}\right)$ and a close-to-particle-free environment. An aerosol sampling line was connected to the PDSP outlet as shown in Fig. 2. The sampling line was made of stainless steel and equipped with an X-connector (1/4" size) used to supply an air flow of $1.0 \mathrm{~L} \mathrm{~min}^{-1}$ to minimize condensation-one of the lines of connector was plugged in these tests. The aerosol sample was diluted with an additional air flow of $16.5 \mathrm{~L} \mathrm{~min}^{-1}$ via a line (1/4" size) connected to an X-connector ( $1 / 2^{\prime \prime}$ size). Both dilution steps were operated at $20^{\circ} \mathrm{C}$ in this study. All air flows were supplied using mass flow controllers (S5851-S; Brooks Instrument). The excess air flows in the set-up were directed to an exhaust line.

The diluted, suspended particulate matter of the smoke/aerosol samples was collected on a 400-mesh perforated-carbon-film-coated copper TEM grids (Agar Scientific; Fig. 3) in view of analyzing them using SEM technique. The particulate matter sampling was performed directly from the aerosol flow by passing a sample flow of $0.5 \mathrm{~L} \mathrm{~min}^{-1}$ through the grid-a pump coupled with a critical orifice was used to generate and control the aerosol flow. The main collection



Fig. 2. Aerosol dilution method: mainstream aerosol generation, dilution and collection. 


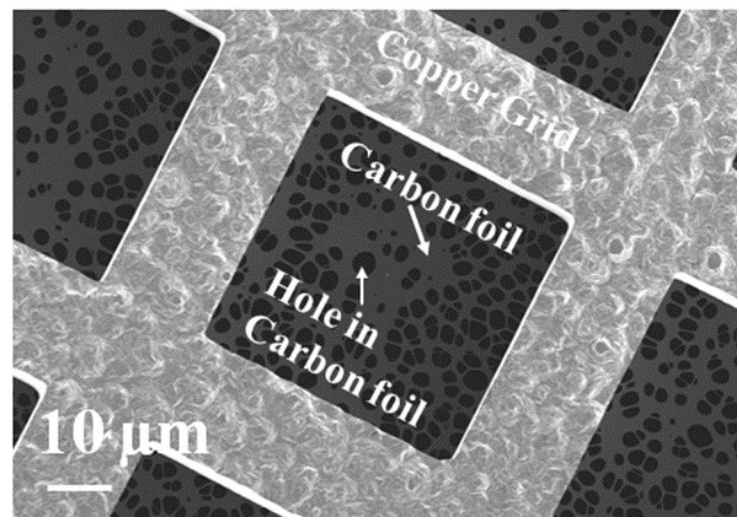

Fig. 3. TEM grid equipped with a perforated carbon foil. This image contains three important features that are the copper grid in light grey, the perforated carbon foil in dark grey and the perforations (holes) as dark spots on the carbon foil.

mechanism for particulate matter was diffusion to the grid surface (Ogura et al., 2014). For particle sizes in an operational range from 5 to $150 \mathrm{~nm}$ (R'mili et al., 2013; Ogura et al., 2014; Xiang et al., 2019), a minimum collection efficiency of $15-18 \%$ has been reported for about 30-nmsized particles. For the particles less than $30 \mathrm{~nm}$ in diameter (the particle collection takes place mainly via diffusional deposition), the collection efficiency increases significantly, being in the range of 70-95\% for particle sizes below $5 \mathrm{~nm}$. Regardless the particle size, the TEM grid sampling method is able to collect a sample of all particle sizes (with varying collection efficiencies) covering the most penetrating nanoparticle sizes as well.

Some of the TEM grids with the collected particle samples were placed on an aluminum-foilcovered sample holder (made of alumina $\left[\mathrm{Al}_{2} \mathrm{O}_{3}\right]$ ), which was positioned in a tubular furnace with a stainless steel furnace tube. The TEM grids were heated at $200^{\circ} \mathrm{C}$ for an hour in a dry air flow of $0.4 \mathrm{~L} \mathrm{~min} \mathrm{mi}^{-1}$. It enabled the vaporization of low-boiling-point species and the subsequent analysis of residual deposits.

\subsection{Method B: Thermo-denuded Aerosol}

For this method, the collection process was performed in the PMI facilities and the analyses by Microscan Service SA. A schematic diagram of the thermo-denuded aerosol method is shown in Fig. 4. The approach used to characterize the aerosol from the EHTPs is described in Pratte et al. (2017). In this approach, a Dekati thermo-denuder was operated at a temperature of $300^{\circ} \mathrm{C}$, which is close to the boiling point of glycerin $\left(290^{\circ} \mathrm{C}\right)$, the main aerosol former used to form the droplets constituting the EHTS aerosol. The thermo-denuder consists of two parts. A first section corresponding to a 1-m-long curved and a 1-m-long straight tubing heated at $300^{\circ} \mathrm{C}$, embedded in a thermally insulated material. The second part is composed of a $0.60-\mathrm{m}$-long gas stripper enabling volatiles to be captured on an active carbon-based replaceable cartridge. The cartridges were replaced every $20 \mathrm{~h}$ of operation. To make sure the gas stripper was used in optimal operating

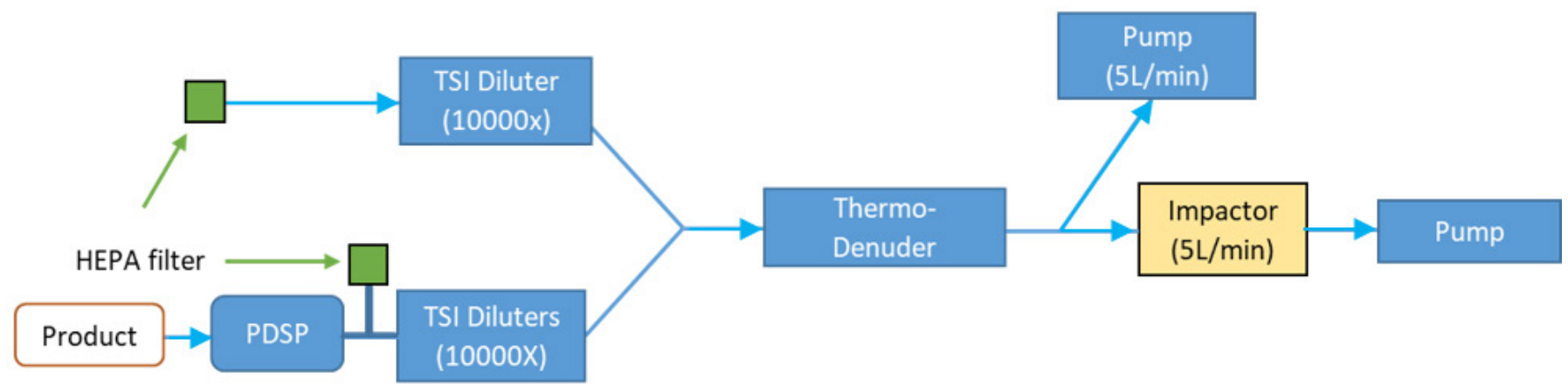

Fig. 4. Thermo-denuded aerosol method: mainstream aerosol generation, thermo-denuding, and collection. 

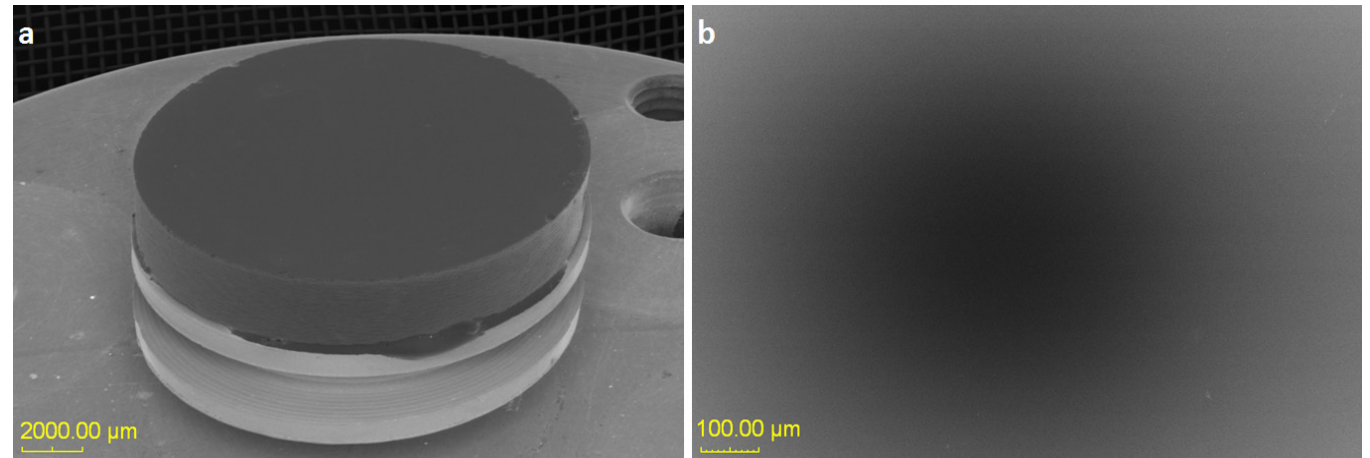

Fig. 5. Illustration of collection surfaces. (a) Clean polished vitreous carbon surfaces fixed on SEM aluminium stubs used in the impactor trap. (b) Clean collection surface before impaction.

conditions, $70 \mathrm{~L} \mathrm{~min}^{-1}$ of compressed air at room temperature was flowed into its housing so that volatiles were trapped efficiently on the carbon-based filter to minimize potential re-condensation. Prior to generating the aerosol, the total flow passing through the thermo-denuder was set at $10 \mathrm{~L} \mathrm{~min}{ }^{-1}$. This was done by pumping a flow through a TSI 3708 4-way flow splitter, ensuring the sampling flow was split equally to a filter-protected vacuum pump and in a two-stage impactor trap (Jalanti and Henchoz, 1990) for which the potential residual particulate matter was analyzed.

Upstream the thermo-denuder, two TSI dilution units were installed and connected to each of the two aerosol transportation lines. The first line was connected to the outlet of the programmable dual-syringe pump (Burkhart Messtechnik GmbH, Wedel, Germany) to generate an aerosol in the TSI dilution units operated at a volumetric flow rate of $5 \mathrm{~L} \mathrm{~min}{ }^{-1}$. The second line used $5 \mathrm{~L} \mathrm{~min}^{-1}$ of laboratory make-up air that was recombined with the diluted aerosol stream prior to entering the thermo-denuder. Each of the aerosol diluter unit was set to a dilution ratio of 100 to avoid the saturation of the thermo-denuder, resulting in an overall dilution of 10,000 (two diluters in a series). The second line was needed to dilute the laboratory make-up air and to ensure the volumetric flow rates were identical in the two transport lines as the flow rates could have differed due to the corresponding pressure drop. To generate an aerosol from the tested product, a PDSP was operated using the Health Canada Intense regimen (10 puffs for 3R4F reference cigarettes and 12 puffs for the EHTS).

The impactor collected the aerosol particles directly on a polished sampling surface, fixed to a SEM specimen stub (Fig. 5). The suitable surface material was selected to be vitreous carbon to minimize X-ray background. Regarding the impaction process, an air sample containing airborne contaminants was aspired through a thin nozzle placed in front of the collection surface. The large/heavy particles impacted on the surface owing to their inertia while the smaller/lighter ones followed the streamlines of the air flow. The use of two different stages of various geometries (nozzles sizes, distance between nozzles and the collection surface) allowed to size-segregate the particles in two size fractions. The first stage collected the supermicron particles and the second the submicron particles.

The collection efficiency of this method for particles depends on the geometry of the device (impactor) as well as the size and mass of the particles. Particles smaller than $1 \mu \mathrm{m}$ are collected on the second stage of impactor. In general, only particles larger than $20 \mathrm{~nm}$ are considered for analyses for the reasons related to analytical equipment (Pratte et al., 2017). A fraction of the submicron-sized particles is not trapped by the device (particles are too small or too light) and the particles continue their course in the air flow. A new study is currently underway to characterize more precisely the device by carrying out simulations and tests with calibrated particles. In the long term, it will make possible to obtain quantitative results. The measurements made for this item are relative and not absolute. They are compared to the measurements of blank tests ("not contaminated with particulate matter") and standard cigarettes ("fully contaminated with particulate matter").

\subsection{Electron Microscopy}

For the aerosol samples collected using the dilution method (see Section 3.1), the morphology 
of the trapped particulate matter was analyzed using an SEM (Zeiss Crossbeam 540). The resulting SEM images were obtained using the in-lens secondary electron (SE) detector, located above the objective lens in the SEM column. The in-lens detector is a high-contrast device allowing fast imaging, generally used for beam-sensitive samples or for the detection weak intensity signal from very thin objects such as the EHTS aerosol specimens. The SEM was operated at an acceleration voltage between 2-4 kV for imaging. The probe current used during SEM analyses was set to approximately $100 \mathrm{pA}$. To especially consider the detection performance of SEM for the nanoparticles analyzed from the samples of the dilution method, it can be concluded that it is not a limitation with respect to the detection of nanometer-sized particles. The instrument has specific resolution of $0.9 \mathrm{~nm}$ at $15 \mathrm{kV}$ and $1.8 \mathrm{~nm}$ at $1 \mathrm{kV}$. Thus, particles less than $5 \mathrm{~nm}$ can be analyzed. The SEM is equipped with a plasma cleaner, periodically used to clean the specimen's chamber.

For the thermo-denuded aerosol samples, the collection surfaces were mounted on an SEM stub, removed from the impactor under clean-air conditions, fixed on the SEM holder (in laminar flow hood) and directly transferred into the SEM chamber. The morphology of the particulate matter samples was analyzed using FEG-SEM (Zeiss Sigma). The SEM was operated at an acceleration voltage of $5 \mathrm{kV}$, using the in-lens SE detector. Only particles larger than $20 \mathrm{~nm}$ were considered for the analysis, as described in Section 3.2. The collection surface cleanliness is verified before assembling the impactor traps. The SEM calibration was controlled using certified samples before performing any analysis. The determination of the projected area of impacted particles was performed by image analysis using ImageJ and Atlas Software.

\section{TEST CONDITIONS}

The different EHTP versions were tested at various conditions, shown in Table 1. The tests were performed using two different methods, as described above. In order to compare the results with the combusted cigarette, the reference $3 \mathrm{R} 4 \mathrm{~F}$ tests are also indicated.

Table 1. Testing conditions for the two tested approaches: $(A)$ aerosol dilution method, (B) thermo-denuded aerosol method. In the three tests using heated EHTP and one test using 3R4F (Method A), the collected particulate samples was also further heated in a furnace at $200^{\circ} \mathrm{C}$ in an air atmosphere for an hour.

\begin{tabular}{|c|c|c|c|c|c|}
\hline Method & Type of product & $\begin{array}{l}\text { Number of } \\
\text { product used } \\
\text { per test }\end{array}$ & $\begin{array}{l}\text { Applied } \\
\text { dilution }\end{array}$ & Test type & Testing conditions \\
\hline A & $\begin{array}{l}\text { Non-heated EHTP without } \\
\text { filter elements }\end{array}$ & 1 & 300 & $\begin{array}{l}\text { Aerosol dilution at room } \\
\text { temperature }\end{array}$ & 1 puff, $55 \mathrm{~mL}$ puff in $2 \mathrm{~s}$ \\
\hline A & $\begin{array}{l}\text { Heated EHTP without } \\
\text { filter elements }\end{array}$ & 1 & 300 & $\begin{array}{l}\text { Aerosol dilution at room } \\
\text { temperature }\end{array}$ & 1 puff, $55 \mathrm{~mL}$ puff in $2 \mathrm{~s}$ \\
\hline A & $\begin{array}{l}\text { Heated EHTP with filter } \\
\text { elements }\end{array}$ & 1 & 300 & $\begin{array}{l}\text { Aerosol dilution at room } \\
\text { temperature }\end{array}$ & 1 puff, $55 \mathrm{~mL}$ puff in $2 \mathrm{~s}$ \\
\hline A & $\begin{array}{l}\text { Heated EHTP with filter } \\
\text { elements }\end{array}$ & 1 & 300 & $\begin{array}{l}\text { Aerosol dilution at room } \\
\text { temperature }\end{array}$ & 11 puffs, $55 \mathrm{~mL}$ puff in $2 \mathrm{~s}$ \\
\hline$A$ & $3 R 4 F$ & 1 & 300 & $\begin{array}{l}\text { Aerosol dilution at room } \\
\text { temperature }\end{array}$ & 10 puffs, $55 \mathrm{~mL}$ puff in $2 \mathrm{~s}$ \\
\hline B & $\begin{array}{l}\text { Blank: HEPA-filtrated } \\
\text { laboratory air }\end{array}$ & $\mathrm{N} / \mathrm{A}$ & 10,000 & Thermo-denuder at $300^{\circ} \mathrm{C}$ & 12 puffs, $55 \mathrm{~mL}$ puff in $2 \mathrm{~s}$ \\
\hline B & $\begin{array}{l}\text { Not heated EHTP with } \\
\quad \text { filter elements }\end{array}$ & 2 & 10,000 & Thermo-denuder at $300^{\circ} \mathrm{C}$ & 12 puffs, $55 \mathrm{~mL}$ puff in $2 \mathrm{~s}$ \\
\hline B & $\begin{array}{l}\text { Not heated EHTP without } \\
\text { filter elements }\end{array}$ & 2 & 10,000 & Thermo-denuder at $300^{\circ} \mathrm{C}$ & 12 puffs, $55 \mathrm{~mL}$ puff in $2 \mathrm{~s}$ \\
\hline B & $\begin{array}{l}\text { Heated EHTP with filter } \\
\text { elements }\end{array}$ & 2 & 10,000 & Thermo-denuder at $300^{\circ} \mathrm{C}$ & 12 puffs, $55 \mathrm{~mL}$ puff in $2 \mathrm{~s}$ \\
\hline B & $\begin{array}{l}\text { Heated EHTP without } \\
\text { filter elements }\end{array}$ & 2 & 10,000 & Thermo-denuder at $300^{\circ} \mathrm{C}$ & 12 puffs, $55 \mathrm{~mL}$ puff in $2 \mathrm{~s}$ \\
\hline B & 3R4F (Pratte et al., 2017) & 2 & 10,000 & Thermo-denuder at $300^{\circ} \mathrm{C}$ & 10 puffs, $55 \mathrm{~mL}$ puff in $2 \mathrm{~s}$ \\
\hline
\end{tabular}




\section{RESULTS}

\subsection{Diluted Aerosol and Characterization}

To evaluate whether or not a heated EHTP without filter elements generates solid particles, tests using a non-heated EHTP without filter elements, a heated EHTP with filter elements, as well as a combusted $3 \mathrm{R} 4 \mathrm{~F}$ reference cigarette were conducted and used as comparators. The SEM images resulting from the tests on EHTPs are summarized in Fig. 6. Only 1 puff was drawn per the different EHTP versions to ensure a particulate matter thin deposition layer on the TEM grid to avoid aggregation of particles and enable single-solid-particle detection and the analysis of them using SEM. As a reference sample, a modified EHTP without filter elements was inserted into the EHTS holder and a puff was drawn without the heating switched on. The aim was to assess if there were any solid particles originating from either impurities in the air, from the test system, or from fragments stripped off the modified EHTP without filter elements by the air flow during puffing. The images displayed in Figs. 6(a) and 6(b) indicated that even without heating, some solid particles were observed (impurities), coming from air and surfaces of the test system. This reference test was done to be able to evaluate if a significant number of particles are generated during the heating of the tobacco during EHTS use. The associated images (Figs. 6(c) and 6(d)) indicate the presence of particulate matter layers without distinct features indicating that the deposited particulate matter is liquid-based. Upon heating the sample in a furnace at $200^{\circ} \mathrm{C}$ for an hour (under air flow of $0.4 \mathrm{~L} \mathrm{~min}^{-1}$ ), the layers evaporated (Fig. 6(e)) demonstrating their volatile nature. The liquid-based layers observed are most likely constituted of deposited glycerin, originating from the tobacco material in the EHTP to which it is added as an aerosol former during its fabrication. To complete the tests, a puff was generated using a heated EHTP with filter elements. As shown in Figs. 6(f) and 6(g), similar featureless particulate matter layers were observed as those for the modified EHTP without filter elements. Again, upon heating the sample in a furnace at $200^{\circ} \mathrm{C}$ for an hour, the layers evaporated (Fig. 6(h)). This shows that irrespective of the presence

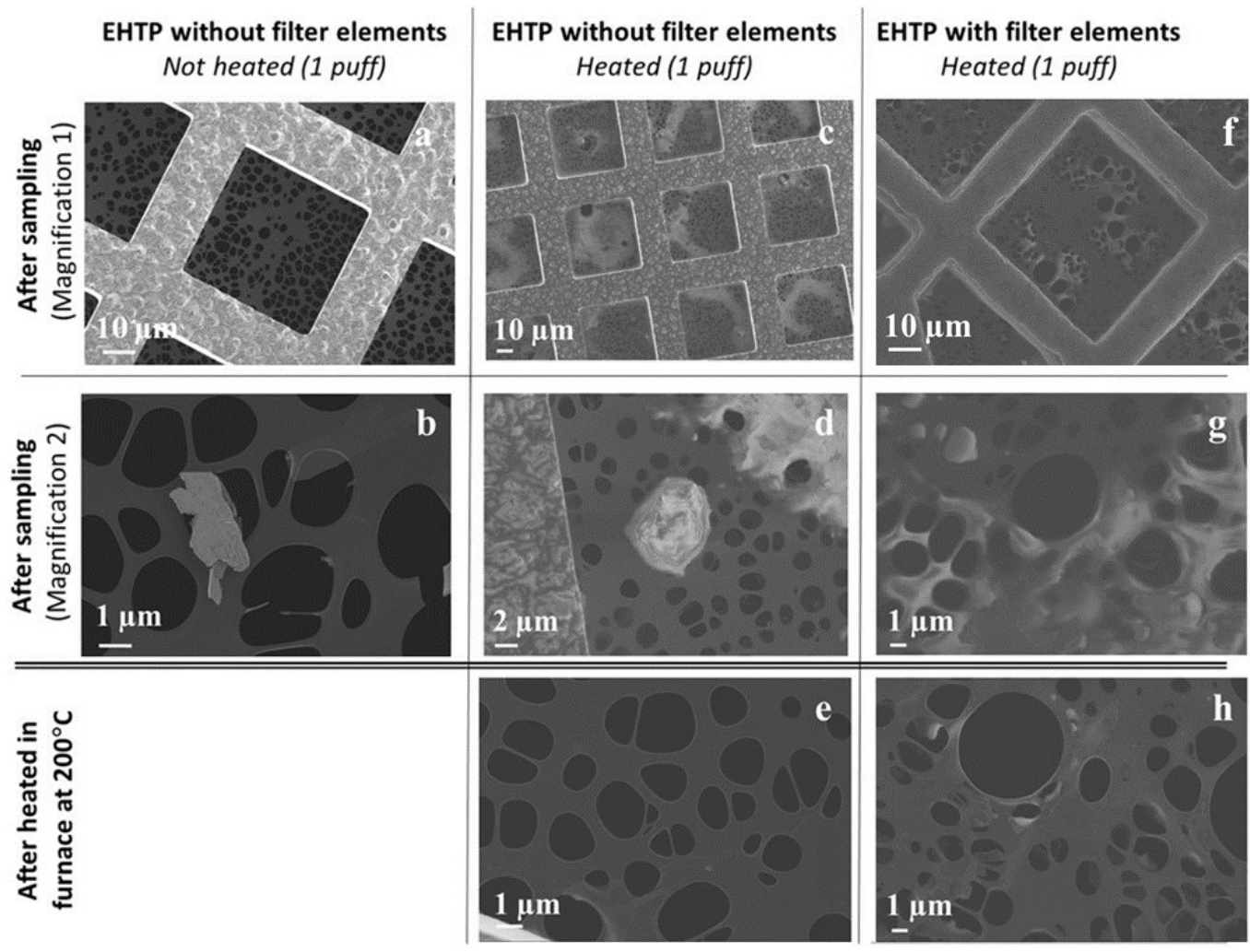

Fig. 6. SEM images for tests performed using different EHTP configurations. From left to right: modified EHTP without filter elements (not heated), modified EHTP without filter elements (heated), and EHTP with filter elements (heated). 
of the filter elements, the deposited particulate matter is constituted of organic volatile compounds. Interestingly, after the samples were heated in the furnace at $200^{\circ} \mathrm{C}$ for an hour, the images associated to the modified EHTP without filter elements (Fig. 6(e)) and the EHTP with filter elements (Fig. 6(h)) were comparable to the image of the reference sample where a puff was drawn on a non-heated EHTP without filter elements (Figs. 6(a) and 6(b)). This indicates that the heating of the EHTP tobacco does not lead to the formation of solid particles.

To position the observed results from the EHTP presented above in the context of combusted tobacco products, similar tests were performed for both a heated EHTP with filter elements (11 puffs) and for a combusted 3R4F reference cigarette (10 puffs). In comparison to the above presented EHTP examination, the numerous puffs generated per tobacco product ensured a notable build-up of the potential particulate matter deposition on TEM grid. It enabled favorable conditions for the verification of the solid particle presence or absence when the TEM grid was heated in the next step, leaving only the residual solid deposit on the TEM grid (see below). The analysis of solid particle formation from the thick deposition layer would not have been possible without the heating of deposits and the subsequent vaporization of volatile species from the deposits. The difference in puff number (10 or 11 puffs) did not play a big role in the analysis of solid particle formation. The associated SEM images are displayed in Fig. 7 for the collected cigarette smoke (Fig. 7(a)) and for the collected aerosol produced by the heated EHTP with filter elements (Fig. 7(c)). Both images (Figs. 7(a) and 7(c)) are showing the presence of mostly featureless particulate matter layers. However, in the image of the collected cigarette smoke, particles with distinct features can also be identified (Fig. 7(a)). Upon heating the samples independently in a furnace at $200^{\circ} \mathrm{C}$ for an hour, the featureless semi-volatile particulate matter evaporated resulting in the SEM images displayed in Figs. 7(b) and 7(d). In the case of the heated EHTP with filter elements, the particulate matter layer evaporated, indicating that EHTP aerosol is liquid-based and does not contain solid particles coming from the heating (Fig. 7(d)). In contrast, for the collected cigarette smoke the semi-volatile compounds evaporated during the temperature treatment at $200^{\circ} \mathrm{C}$ for an hour, revealing the presence of a myriad of solid particles (Fig. 7(b)) formed and emitted during combustion. This clearly shows that combusted tobacco products produce and release combustion-related solid particles whereas the tobacco in EHTPs is heated and not combusted, forming a liquid-based aerosol free of heating- and combustion-related solid particles.

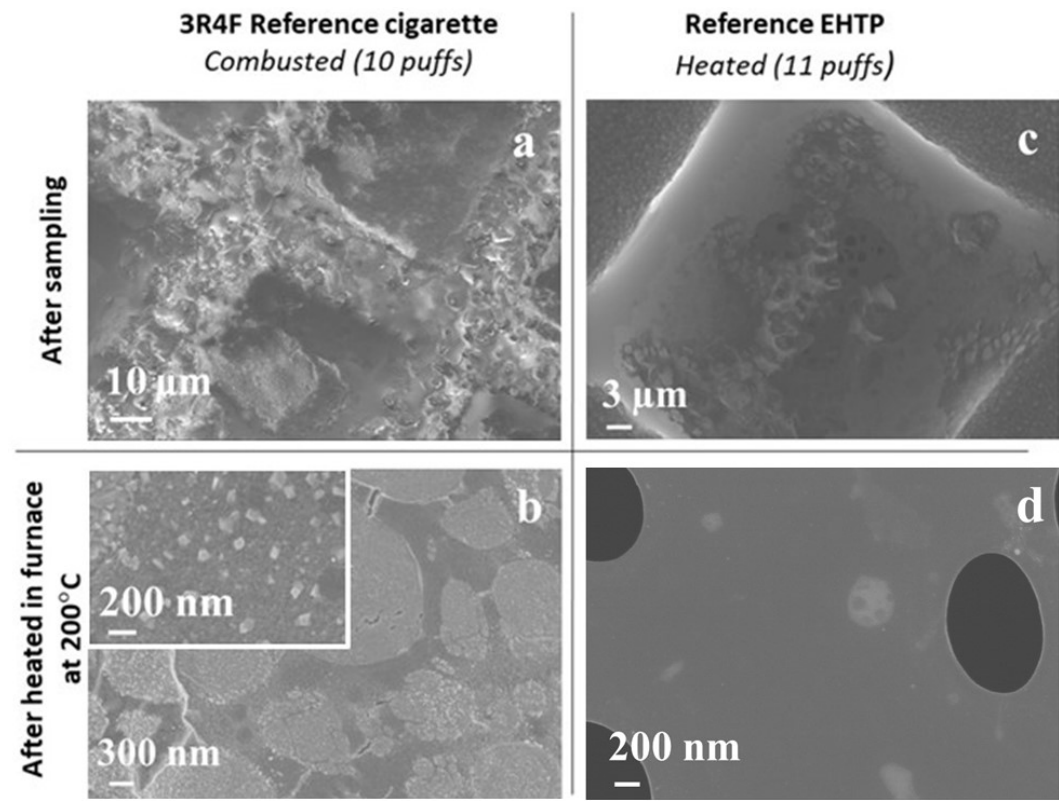

Fig. 7. SEM images of (c) the aerosol collected from heated EHTP with filter elements from 11 puffs in comparison to (a) collected 3R4F cigarette smoke from 10 puffs. After a thermal treatment of the collected samples in a furnace at $200^{\circ} \mathrm{C}$ for an hour, images are shown for (d) the heated EHTP with filter elements and for (b) cigarette smoke with a magnified section of the area with solid particles. 


\subsection{Thermo-denuded Aerosol and Characterization}

Prior to performing the assessment of the modified EHTP without filter elements using the thermo-denuder set-up (Fig. 4), a blank experiment was performed to evaluate the contamination that may have come from the system. The blank was obtained by using a high-efficiency particulate air (HEPA) filter placed at the inlet of the PDSP instead of the modified EHTP and the $\mathrm{HCl}$ regimen was applied. The potential suspended particulate matter passed through the dilution units, the thermo-denuder and finally was impacted in a two-stage impactor. The SEM images of the impaction area of both stages are illustrated by Figs. 8(a) and 9(a). For both stages (supermicron and submicron collection), a low contamination level is observed for the blank experiment, which validates the cleanliness of the device experiment. The solid particulate deposit of each test using EHTP and 3R4F products are displayed in Figs. 8 and 9.

To evaluate the effect of removing filter elements on the potential emission of solid particles from the heating process, a non-heated and heated original EHTP with filter elements were tested as a reference. The images in Fig. 8 and 9 are taken in the center of the impaction spots of each stage.

Except for the 3R4F sample, the SEM images show a very low level of supermicron and submicron particulate deposit. To illustrate the substantial particulate deposit on the collection surface of
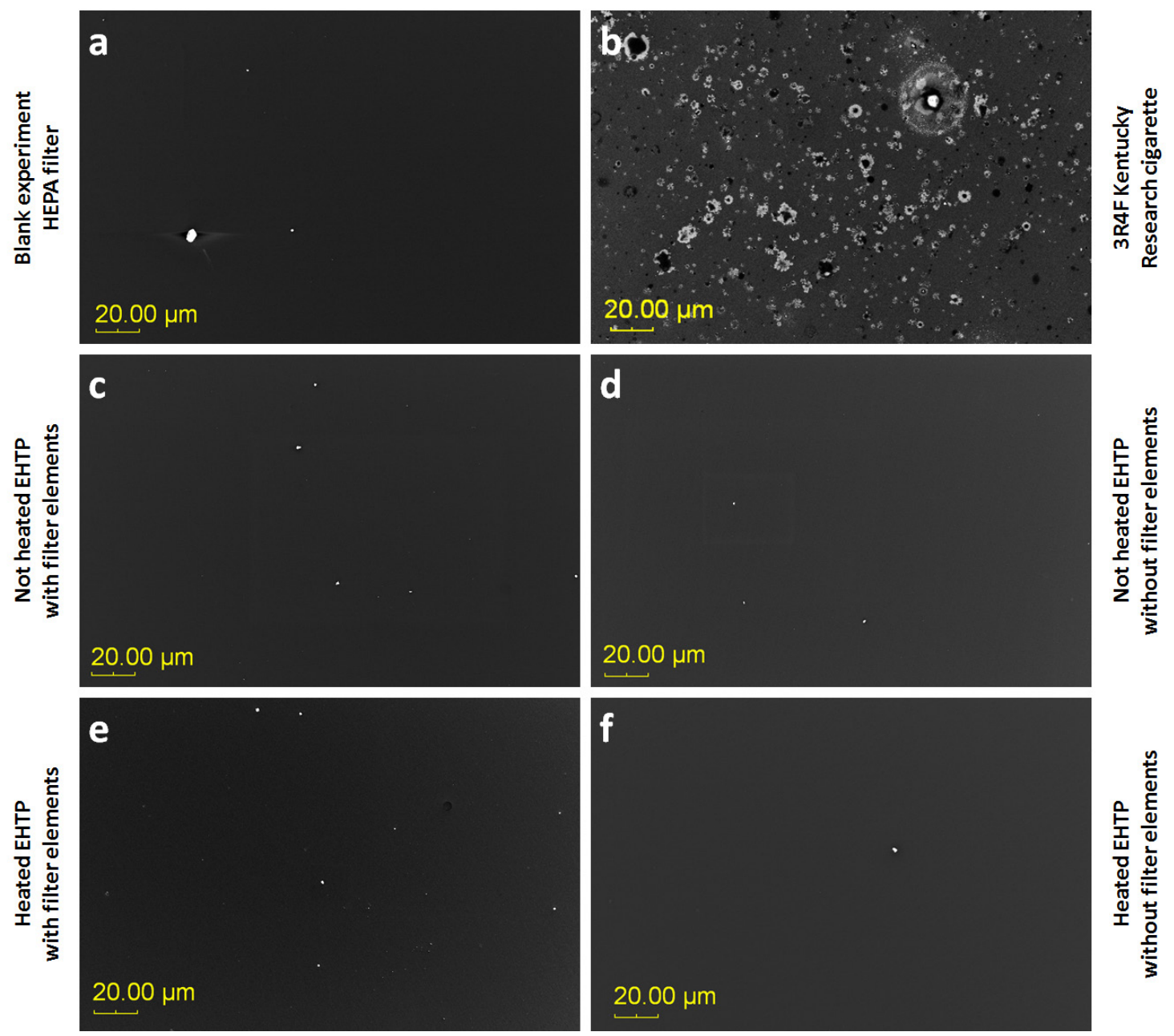

Fig. 8. The first-stage SEM in-lens secondary electrons detector images for the thermo-denuder experiment. (a) The blank experiment was performed by replacing Product in Fig. 4 with a HEPA filter. (b) represents collected thermo-denuded smoke from a reference 3R4F cigarette as documented in the literature (Pratte et al., 2017). The images resulting from the collection of thermo-denuded aerosols are reported for the non-heated EHTP (c) with filter elements and (d) without filter elements. The images resulting from the collection of thermo-denuded aerosols are reported for the heated EHTP (e) with filter elements and (f) without filter elements. 

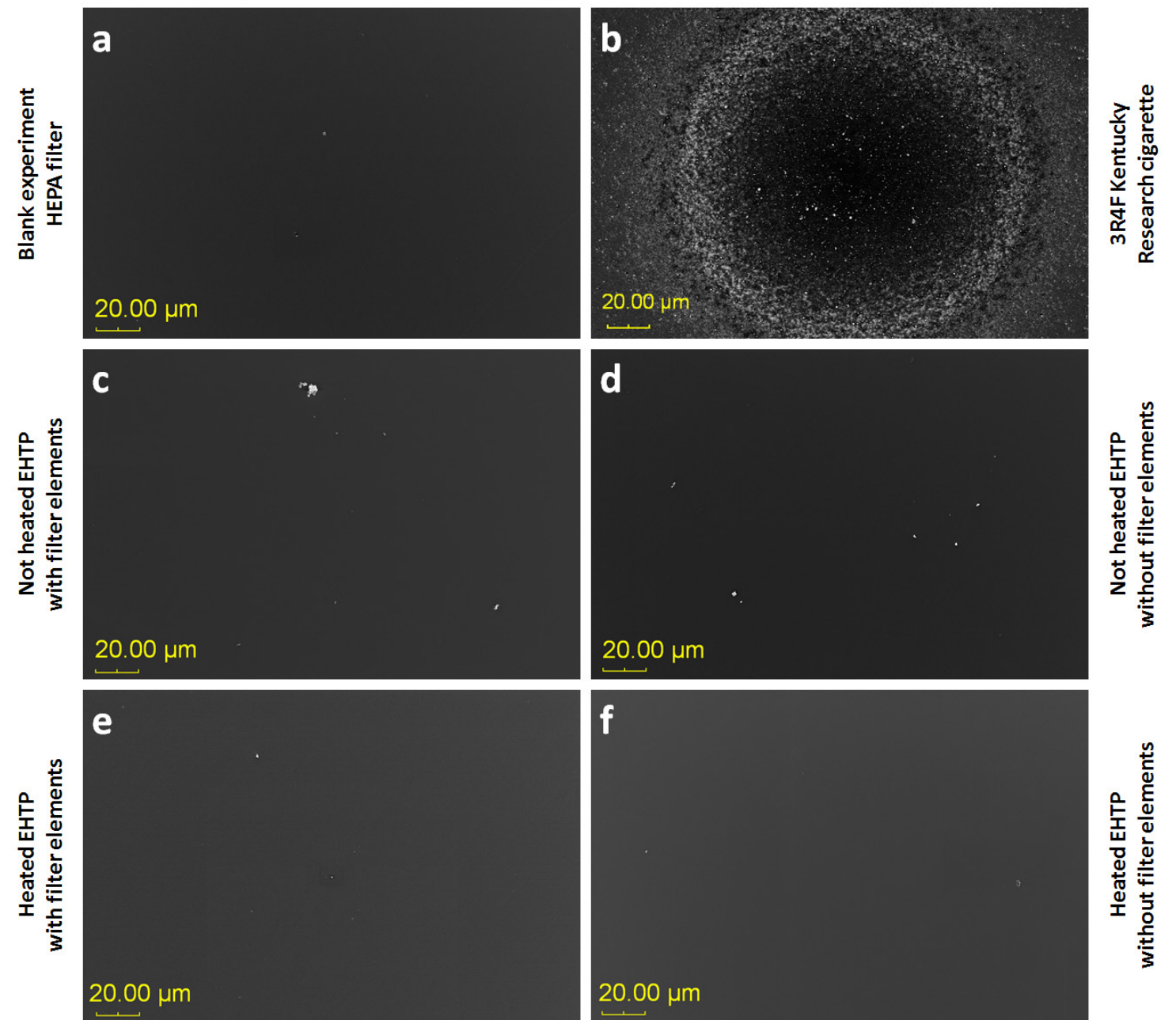

Fig. 9. The second-stage SEM in-lens secondary electrons detector images for the thermo-denuder experiment. The images are located on one of the six impaction areas of the second stage. (a) The blank experiment was performed by replacing "Product" in Fig. 4 with a HEPA filter. (b) Collected thermo-denuded smoke from a reference 3R4F cigarette as documented in the literature (Pratte et al., 2017). The images resulting from the collection of thermo-denuded aerosols are reported for the non-heated EHTP (c) with filter elements and (d) without filter elements. The images resulting from the collection of thermo-denuded aerosols are reported for the heated EHTP (e) with filter elements and (f) without filter elements.

the reference 3R4F cigarette, Fig. 10 represents the surface of the second stage (submicron) after the collection of thermo-denuded smoke from a reference 3R4F cigarette (Fig. 10(a)) compared to a non-used collection surface (Fig. 10(b)).

The projected surface of the impacted particles (particles' projected surface [PPS]) is measured by image treatment software (threshold segmentation) on the images of Figs. 8 and 9 . For the supermicron particles (first stage; Fig. 8), the PPS measured for the non-heated with and without filter elements, heated with and without filter elements were 6.1, 2.3, 8.4 and $2.5 \mu \mathrm{m}^{2}$, respectively (Fig. 11). These values are in the magnitude of the blank sample $\left(22.1 \mu \mathrm{m}^{2}\right)$. For 3R4F experiment, the PPS of 1,972 $\mu \mathrm{m}^{2}$ was measured. To better compare this amount to the blank and non-heated/ heated EHTP experiments, the PPS values were normalized by the PPS of 3R4F cigarette smoke. The associated values were found to be of $0.31 \%, 0.12 \%, 0.42 \%$ and $0.13 \%$, for the non-heated sticks with and without filter elements and for the heated sticks with and without filter elements, respectively. No significant difference with the blank (normalized PPS: $1.12 \%$ ) was observed between the non-heated and the heated sticks, irrespective of the presence of filter elements. Therefore, these values can be considered as background.

For the submicron particles (second stage; Fig. 9), the PPS measured are reported in parentheses for non-heated sticks with filter elements $\left(29.0 \mu \mathrm{m}^{2}\right)$, without filter elements $\left(6.6 \mu \mathrm{m}^{2}\right)$, for 

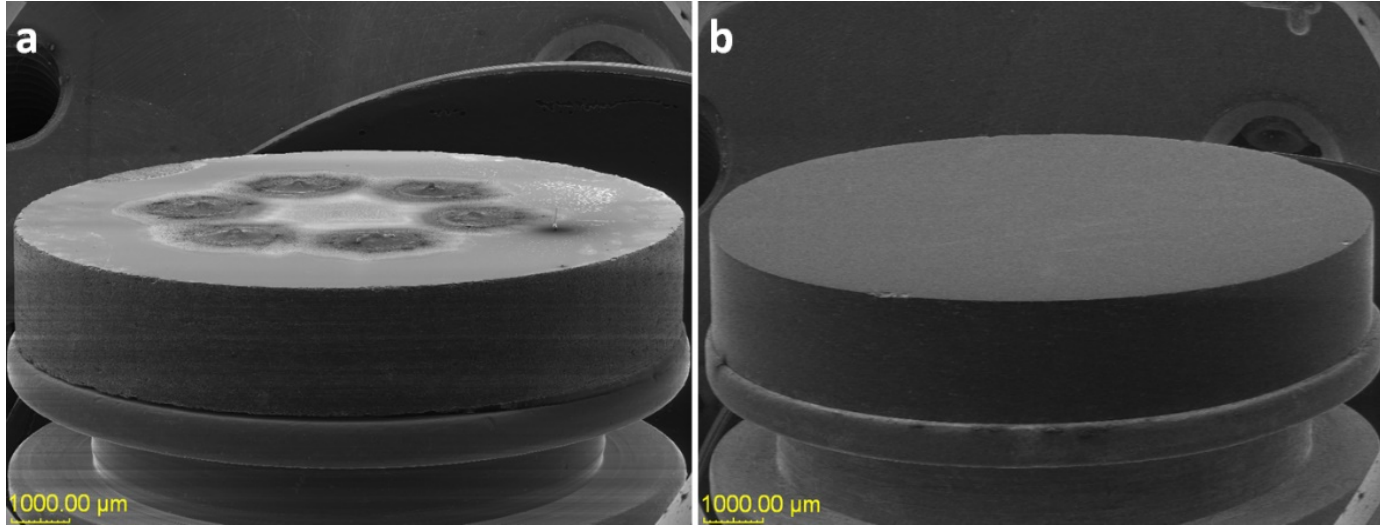

Fig. 10. Comparison of secondary electron detector SEM images between (a) the collection surface of the 3R4F cigarette second stage (submicron) and (b) a non-used surface.
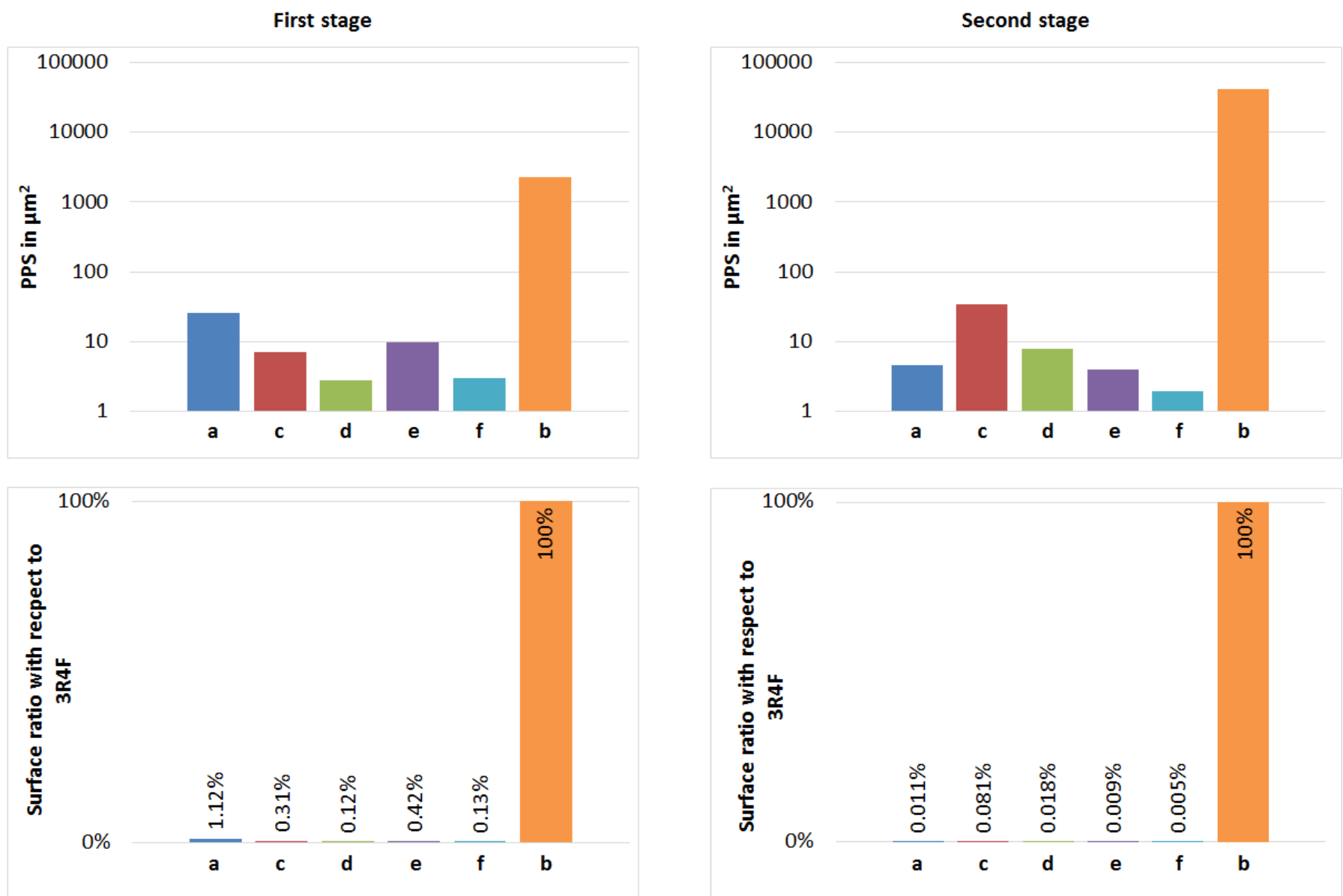

Fig. 11. On the first row, the comparison in logarithmic scale of the particles' projected surfaces (PPSs) on the first-stage impaction area and one of the six impaction areas of the second stage. On the second row, the ratios between the PPS of each test compared to the 3R4F experiment are displayed. The blank experiment with HEPA filter corresponds to $a$, the non-heated EHTP with/without filter elements to $c / d$ and the heated EHTP with/without filter elements to $e / f$. The values of the reference 3R4F cigarette are represented by $b$.

heated sticks with filter element $\left(3.4 \mu \mathrm{m}^{2}\right)$ and without filter elements $\left(1.7 \mu \mathrm{m}^{2}\right)$ (Fig. 11). Except for the non-heated with filter elements, these PPS values are comparable to the blank sample $\left(3.9 \mu \mathrm{m}^{2}\right)$. A coarse particle (probably contamination; second row in Fig. 9) is present for the nonheated EHTP with filter elements sample and explains the higher PPS of $29.0 \mu \mathrm{m}^{2}$. In the 3R4F 
experiment, multiple layers of particles were observed (six small mounds in Fig. 10(a)). In this case the center of the impaction spot was considered as fully covered $\left(35,966 \mu \mathrm{m}^{2}\right)$. When normalized with respect to $3 \mathrm{R} 4 \mathrm{~F}$, the surface coverage values were found comparable for nonheated sticks with filter elements $(0.081 \%)$, without filter elements $(0.018 \%)$, heated sticks with filter element $(0.009 \%)$ and without filter elements $(0.005 \%)$. As for the supermicron particles, these yields are comparable to the background.

Note that most of the 3R4F particles are constituted of submicron particles. The concentration of particles is estimated by using the granulometry of particles of the 3R4F sample previously published (Pratte et al., 2017). In this publication, the size distribution was determined at the edge of the impaction spot. On Fig. 12, the SEM images show the 3R4F smoke particles. The median diameter of the impacted particles was $75 \mathrm{~nm}$. To estimate the total number of particles, they were assumed to be spherical with a representative size of $75 \mathrm{~nm}$. Considering the surface of the six impaction spots, the number of impacted submicron particles were estimated to be $60,000,000$. This particle number estimation is largely underestimated because of the presence of multiple layers of particles in the impaction spots.

In the future, to characterize and quantify more precisely the amount of solid particles contained in cigarette smoke, a new four-stage impactor will be designed using a modeling approach. This new trap will allow to minimize particle aggregations and enable better particle segregation.

\section{CONCLUSIONS}

Pratte et al. (2017) found no combustion-related solid particles in EHTS aerosol, in contrast to cigarette smoke. Kärkelä et al. (2021) also verified the absence of solid particles. We investigated whether the tobacco in the EHTP releases solid particles during heating that may have been trapped by the filter elements in previous studies. To evaluate the potential effects of these filters, we fabricated modified EHTPs that lacked the PLA and mouthpiece filter elements of the standard EHTP. We then employed two different methods, one based on aerosol dilution and

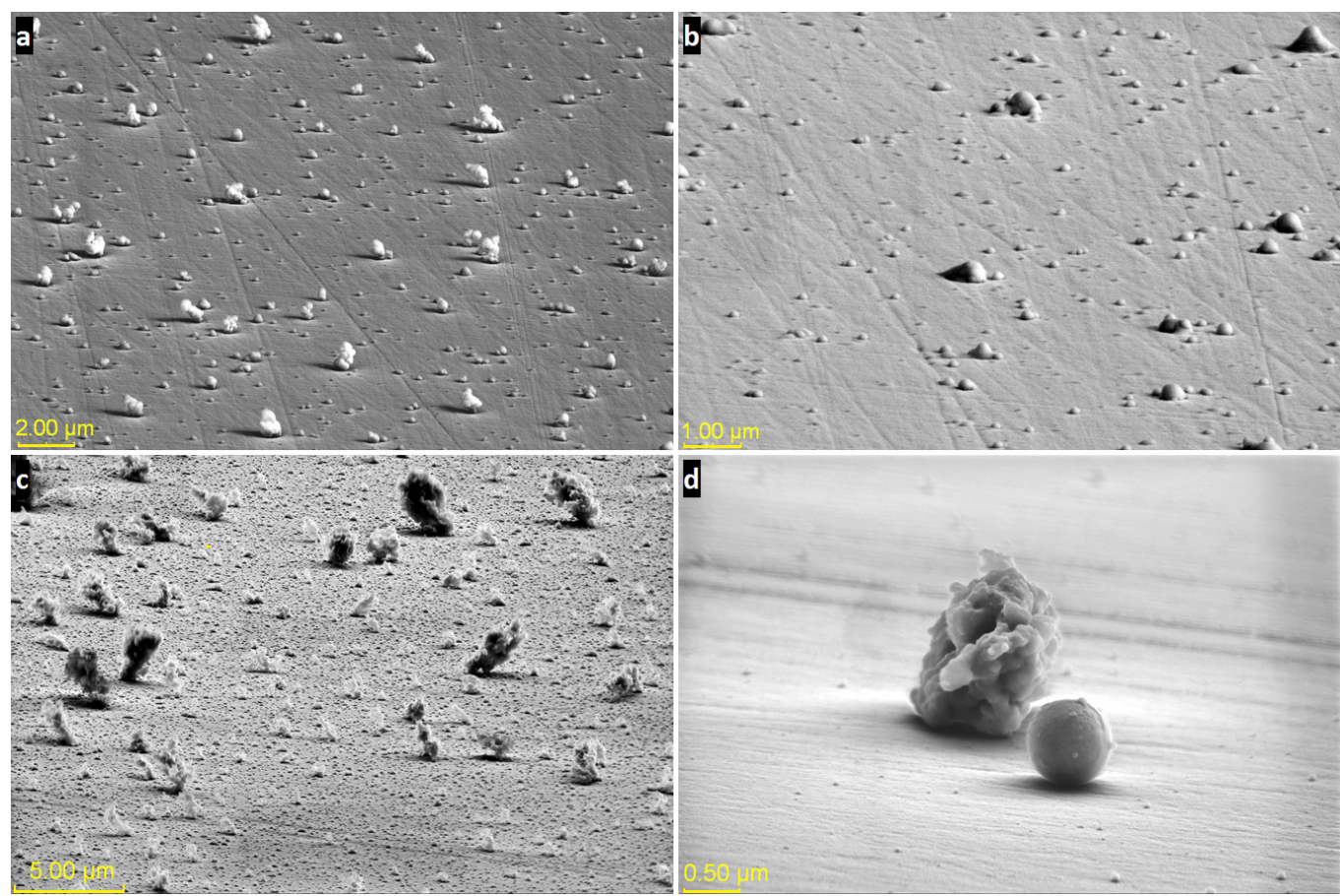

Fig. 12. The edge of an impaction spot on the second stage after the 3R4F experiment: SEM images taken with the $(a, b)$ secondary detector and $(c, d)$ in-lens detector. (a) and (b) illustrate the area corresponding to the determination of the $3 \mathrm{R} 4 \mathrm{~F}$ cigarette smoke size distribution. (c) is closer to the impaction spot because of the substantial particles density. (d) shows one spherical particle, typical to a smoke particle, and a bigger aggregated smoke residue. 
the other, on aerosol thermo-denudement, to analyze the aerosol emitted by the modified EHTP when operated as part of the EHTS and compared it to that of the standard EHTP as well as the smoke generated by the reference 3R4F cigarette. We also complemented both methods with SEM analysis.

Our results indicate that, unlike cigarette smoke, which consists of both liquid and solid particles produced during tobacco burning, the liquid-based EHTP aerosol (for both the modified and the standard model) contains no solid particles related to either tobacco heating or combustion (the latter of which does not occur in the EHTP). Based on the accuracy and reliability of the applied sampling methods and SEM instruments, this conclusion is valid for particles above $\sim 2 \mathrm{~nm}$ in diameter.

\section{ACKNOWLEDGMENTS}

The financial support of Philip Morris International is acknowledged as well as their help with the aerosol collection for Experimental Method B.

\section{REFERENCES}

3R4F research cigarette (2020). University of Kentucky, Lexington, KY, USA. https://ctrp.uk y.edu/products/gallery/Reference\%20Cigarettes/detail/936 (accessed 23 December 2020).

Arden Pope III, C., Burnett, R.T., Thun, M.J., Calle, E.E., Krewski, D., Ito, K., Thurston, G.D. (2002). Lung cancer, cardiopulmonary mortality, and long-term exposure to fine particulate air pollution. JAMA 287, 1132-1141. https://doi.org/10.1001/jama.287.9.1132

Baker, R.R. (1975). Temperature variation within a cigarette combustion coal during the smoking cycle. High. Temp. Sci. 7, 236-247.

Bauer, M., Moebus, S., Möhlenkamp, S., Dragano, N., Nonnemacher, M., Fuchsluger, M., Kessler, C., Jakobs, H., Memmesheimer, M., Erbel, R., Jöckel, K.H., Hoffmann, B. (2010). Urban particulate matter air pollution is associated with subclinical atherosclerosis: Results from the HNR (Heinz Nixdorf Recall) study. J. Am. Coll. Cardiol. 56, 1803-1808. https://doi.org/10.1016/ j.jacc.2010.04.065

Butler, K.M., Mulholland, G.W. (2004). Generation and transport of smoke components. Fire Technol. 40, 149-176. https://doi.org/10.1023/b:fire.0000016841.07530.64

Cozzani, V., Barontini, F., McGrath, T., Mahler, B., Nordlund, M., Smith, M., Schaller, J.P., Zuber, G. (2020). An experimental investigation into the operation of electrically heated tobacco system. Thermochim. Acta 684, 178475. https://doi.org/10.1016/j.tca.2019.178475

Doll, R., Peto, R., Boreham, J., Sutherland, I. (2004). Mortality in relation to smoking: 50 years' observations on male British doctors. BMJ 328, 1519. https://doi.org/10.1136/bmj.38142.554 479.AE

Donaldson, K., Li, X.Y., MacNee, W. (1998). Ultrafine (nanometre) particle mediated lung injury. J. Aerosol Sci. 29, 553-560. https://doi.org/10.1016/s0021-8502(97)00464-3

Fariss, M.W., Gilmour, M.I., Reilly, C.A., Liedtke, W. (2013). Emerging mechanistic targets in lung injury induced by combustion-generated particles. Toxicol. Sci. 132, 253-267. https://doi.org/ 10.1093/toxsci/kft074

Health Canada (2000). Health Canada - Tobacco Products Information Regulations SOR/2000-273, Schedule 2. http://laws-lois.justice.gc.ca/PDF/SOR-2000-273.pdf

Jalanti, T., Henchoz, P. (1990). Analytical scanning electron microscopy: A most important aid for solving microcontamination problems. Swiss Contam. Control 3, 428-432.

Kärkelä, T., Tapper, U., Kajolinna, T. (2021). Comparison of 3R4F cigarette smoke and IQOS heated tobacco product aerosol emissions. Submitted to Environmental Science and Pollution Research.

Klein, S.G., Cambier, S., Hennen, J., Legay, S., Serchi, T., Nelissen, I., Chary, A., Moschini, E., Krein, A., Blömeke, B., Gutleb, A.C. (2017). Endothelial responses of the alveolar barrier in vitro in a dose-contolled exposure to diesel exhaust particulate matter. Part. Fibre Toxicol. 14, 7. https://doi.org/10.1186/s12989-017-0186-4

Ogura, I., Hashimoto, N., Kotake, M., Sakurai, H., Kishimoto, A., Honda, K. (2014). Aerosol particle 
collection efficiency of holey carbon film-coated TEM grids. Aerosol Sci. Technol. 48, 758-767. https://doi.org/10.1080/02786826.2014.924614

Pratte, P., Cosandey, S., Goujon Ginglinger, C. (2017). Investigation of solid particles in the mainstream aerosol of the Tobacco Heating System THS2.2 and mainstream smoke of a 3R4F reference cigarette. Human Exp. Toxicol. 36, 1115-1120. https://doi.org/10.1177/096032711 6681653

R'mili, B., Le Bihan, O, Dutouquet, C., Aguerre-Charriol, O., Frejafon, E. (2013). Particle sampling by TEM grid filtration. Aerosol Sci. Technol. 47, 767-775. https://doi.org/10.1080/02786826.2 013.789478

Rodgman, A. and Perfetti, T.A. (2013). The Chemical Components of Tobacco and Tobacco Smoke. CRC press, Boca Raton, FL, USA.

Schaller, J.P., Keller, D., Poget, L., Pratte, P., Kaelin, E., McHugh, D., Cudazzo, G., Smart, D., Tricker, A.R., Gautier, L., Yerly, M., Reis Pires, R., Le Bouhellec, S., Ghosh, D., Garcia, E., Hofer, I., Vanscheewijck, P., Maeder, S. (2016). Evaluation of the Tobacco Heating System 2.2. Part 2: chemical composition, genotoxicity, cytotoxicity, and physical properties of the aerosol. Regul. Toxicol. Pharm. 81, S27-S47. https://doi.org/10.1016/j.yrtph.2016.10.001

Smith, M.R., Clark, B., Luedicke, F., Schaller, J.P., Vanscheeuwijck, P., Hoeng, J., Peitsch, M.C. (2016). Evaluation of the tobacco heating system 2.2. Part 1: description of the system and the scientific assessment program. Regul. Toxicol. Pharm. 81, S17-S26. https://doi.org/10.1016/j. yrtph.2016.07.006

Steiner, S., Bisig, C., Petri-Fink, A., Rothen-Rutishauser, B. (2016). Diesel exhaust: Current knowledge of adverse effects and underlying cellular mechanisms. Arch. Toxicol. 90, 15411553. https://doi.org/10.1007/s00204-016-1736-5

US Food and Drug Administration (2012). Harmful and Potentially Harmful Constituents in Tobacco Products and Tobacco Smoke. Established List. Federal Register Food and Drug Administration. 77 FR 20034.

World Health Organisation (WHO) (2008). The scientific basis of tobacco product regulation. Report of a WHO Study Group (TobReg). WHO Technical Report Series 945, Geneva.

Xiang, M., Morgeneyer, M., Philippe, F., Bressot, C. (2019). Airborne nanoparticle (nanoaerosol) sampling efficiency analysis based on filtration on TEM grid. J. Phys. Conf. Ser. 1323, 012002. https://doi.org/10.1088/1742-6596/1323/1/012002

You, R., Lu, W., Shan, M., Berlin, J.M., Samuel, E.L.G., Marcano, D.C., Sun, Z., Sikkema, W.K.A., Yuan, X., Song, L., Hendrix, A.Y., Tour, J.M., Corry, D.B., Kheradmand, F. (2015). Nanoparticulate carbon black in cigarette smoke induces DNA cleavage and Th 17-mediated emphysima. elife 4, e09623. https://doi.org/10.7554/elife.09623 